\title{
Análise produtiva e econômica do pepino japonês submetido a diferentes lâminas de irrigação ${ }^{1}$
}

\author{
Eduardo C. O liveira2, Jacinto de A. Carvalho², W ellington G . da Silva², \\ Fátima C. Rezende ${ }^{2}$, Luiz A. A. G omes ${ }^{3} \&$ Maria C. N. de Jesus ${ }^{4}$
}

\begin{abstract}
RESU MO
O bjetivou-se, com o presente trabalho, uma avaliação técnica e econômica da produtividade do pepino japonês (Cucumis sativus L.) em função de diferentes lâminas de irrigação. 0 experimento foi instalado em casa de vegetação, utilizando-se de um delineamento inteiramente casualizado (DIC), com cinco tratamentos de reposição de água no solo $(50,75,100,125$ e 150\%) e seis repetições. O s resultados permitiram concluir que, de maneira geral, o número e o peso dos frutos da cultura foram afetados pelo déficit e excesso hídrico, aplicados pelos tratamentos. A máxima produtividade obtida foi igual a 45.944 $\mathrm{kg} \mathrm{ha}^{-1}$ com aplicação de $320 \mathrm{~mm}$ e a lâmina ótima econômica foi estimada em 319,5 mm, concluindose que, para o pepino japonês, maiores retornos econômicos são obtidos mantendo-se a cultura com umidade do solo próxima da capacidade de campo, repondo integralmente a quantidade de água consumida.
\end{abstract}

Palavras-chave: produtividade, manejo de irrigação, lâmina ótima econômica

\section{Productive and economic analysis of japanese cucumber under different irrigation depths}

\begin{abstract}
This study had the aim to verify the economic feasibility of japanese cucumber (Cucumis sativus L.) yield under different irrigation depths, cultivated in greenhouse. A completely randomized design (CRD), with five levels of replacement of irrigation water $(50,75,100,125$ and $150 \%)$ and six replications was used. The results showed that the number and fruit weight of crop were affected by treatments of water deficit and excess used for treatments. The maximum productivity obtained was equal to $45,944 \mathrm{~kg} \mathrm{ha}^{-1}$ for a depth of $320 \mathrm{~mm}$ and the economic optimum irrigation depth was estimated at $319.5 \mathrm{~mm}$, concluding that for the japanese cucumber higher economic returns are obtained by keeping the crop with soil water content near field capacity, restoring the full amount of water consumed.
\end{abstract}

Key words: yield, irrigation management, economic optimum irrigation depth

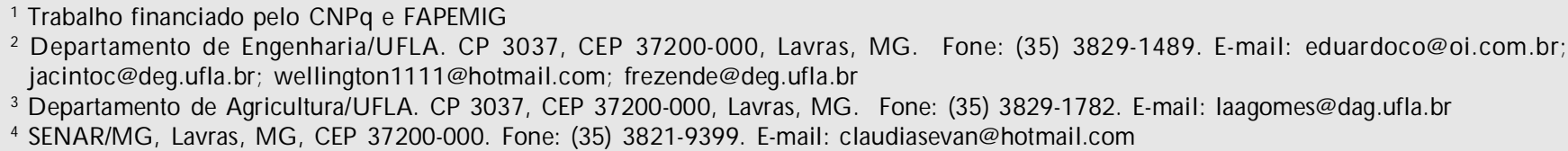




\section{INTRODUÇÃO}

A cultura de pepino se encontra entre as dez hortaliças de maior interesse comercial no Brasil, sendo o pepino japonês uma cultivar bastante apreciada. Seus frutos são preferidos em mercados exigentes, como o da capital paulista, devido ao sabor típico e agradável. Esta cultura, quando tutorada, pode ser conduzida em estufas fechadas, já que seus híbridos são ginóico-partenocárpicos, sendo a polinização indesejável (Filgueira, 2003).

É notório o crescimento da utilização do cultivo em ambiente protegido, uma vez que permite obter produtos de melhor qualidade, aumentar a produtividade e colocar no mercado produtos que, em condições de cultivo em campo não seria possível. Além do controle parcial das condições climáticas, o ambiente protegido reduz os efeitos da sazonalidade.

A irrigação é uma técnica imprescindível sob ambiente protegido; entretanto, o manejo inadequado do sistema de irrigação e da cultura pode inviabilizar o processo produtivo. Vários autores têm comprovado que a irrigação promove aumento na produtividade de diversas hortaliças (Carvalho et al., 2004; Vilas Boas et al., 2008; Dermitas \& Ayas, 2009; Zeng et al., 2009; Bilibio et al., 2010), porém o manejo do sistema de irrigação deve propiciar condições adequadas para potencializar o desenvolvimento e produtividade das culturas. Além disso, o manejo adequado de um projeto de irrigação deve possibilitar maximizar a eficiência do uso da água e minimizar os custos de investimento e operacionais, de forma que a atividade se torne lucrativa e sustentável.

Partindo desta premissa, pode-se afirmar que a prática da irrigação só trará benefícios relacionados a um retorno financeiro maior se feita de forma racional, minimizando os custos com água, energia, equipamentos e outros elementos que constituem fatores de formação dos custos de produção.

Com auxílio de resultados de experimentos agrícolas é possível estimar uma função de produção e o seu ponto ótimo de produção. Define-se uma função de produção como sendo as relações técnicas entre um conjunto específico de fatores envolvidos num processo produtivo qualquer e a produção física possível de se obter com a tecnologia existente (Ferguson, 1988). Desta maneira, conhecidos os preços dos insumos e dos produtos, pode-se determinar a quantidade ótima de cada insumo a ser utilizado para que a lucratividade do agricultor seja otimizada.

Essas funções são obtidas mediante uma análise de regressão entre uma variável dependente e uma ou várias variáveis independentes, segundo determinado modelo, sendo o polinomial quadrático um modelo de função de produção bem representativo para a estimativa de produções agrícolas (Vilas Boas et al., 2007; Silva et al., 2008; Albuquerque Filho et al., 2009; Alencar et al., 2009; Santana et al., 2009; Lima Júnior et al., 2010).

A produtividade pode ser expressa exclusivamente em função da água utilizada pelo cultivo, contando que os demais fatores da produção permaneçam fixos e em nível ótimo. Para que uma atividade agrícola irrigada funcione de maneira racional, dois aspectos devem ser levados em consideração: o retorno econômico da cultura irrigada e os custos de instalação, manutenção e operação do sistema, sendo a irrigação localizada a mais apropriada para culturas de alto retorno econômico (Monteiro, 2004).

A partir daí, este trabalho teve como objetivos avaliar o efeito de cinco lâminas de reposição sobre o rendimento da cultura do pepino japonês, ajustando modelos de regressão das características de produção das plantas como variável dependente das lâminas de reposição de água no solo aliadas a uma análise econômica do processo produtivo.

\section{Material E MÉTODOS}

O trabalho foi conduzido em casa de vegetação situada na área experimental do Departamento de Engenharia da Universidade Federal de Lavras (UFLA), município de Lavras, MG, no período de agosto a novembro de 2008. As coordenadas geográficas da região são: latitude sul de $21^{\circ} 14^{\prime} 00^{\prime \prime}$ e longitude oeste $45^{\circ} 00^{\prime} 00^{\prime \prime}$, com altitude média de aproximadamente 918 m. O clima, de acordo com a classificação de Köppen, é caracterizado como Cwa, sendo temperado suave, chuvoso e com inverno seco. A temperatura média do mês mais quente é de $22,8^{\circ} \mathrm{C}$, a do mês mais frio é de $17,1^{\circ} \mathrm{C}$, e a média anual de 20,4 ${ }^{\circ} \mathrm{C}$ (Dantas et al., 2007).

As condições ambientais foram monitoradas diariamente, através da temperatura e umidade relativa do ar, com o auxílio de um termohigrômetro digital instalado em abrigo no interior da casa de vegetação, cujas leituras eram realizadas diariamente, às $17 \mathrm{~h} 00 \mathrm{~min}$.

O solo da área experimental foi classificado, originalmente, como Latossolo Vermelho Distroférrico. Uma amostra composta representativa foi coletada considerando-se como camada, a altura dos canteiros de $0,25 \mathrm{~m}$; esta amostra foi enviada aos Laboratórios de Física do Solo e de Fertilidade do Solo do Departamento de Ciência do Solo da UFLA para serem realizadas análises físicas e químicas, respectivamente.

De acordo com os resultados das análises físicas, a textura do solo foi classificada como muito argilosa. Além disso, a curva de retenção de água no solo foi determinada para a camada de $0-0,25 \mathrm{~m}$ de profundidade. Para as tensões de 2, 4, 6, 8 e $10 \mathrm{kPa}$ utilizou-se o método do funil de placa porosa e para as tensões de 33, 100, 500 e $1500 \mathrm{kPa}$, a câmara de pressão de Richards. Os parâmetros de ajuste da equação da curva característica de água no solo (verificados na Eq. 1), segundo o modelo de van Genuchten (1980), foram obtidos utilizando-se o software SWRC versão 3.0, de Dourado Neto et al. (2000).

$$
\theta=0,235+\left(\frac{0,674-0,235}{\left[1+(0,2749 \cdot|\psi|)^{2,0272}\right]^{0,5067}}\right)
$$

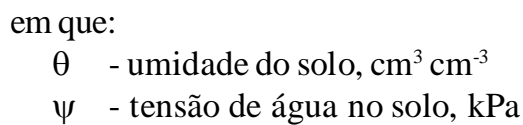


O experimento consistiu em um delineamento inteiramente casualizado (DIC), com cinco percentuais de lâmina de reposição de água no solo (50, 75, 100, 125 e 150\%) como tratamentos e seis repetições. Cada unidade experimental consistiu de um canteiro contendo três plantas espaçadas de $1,1 \times 0,4 \mathrm{~m}$.

Utilizou-se uma válvula controladora no cabeçal de controle para acionar o sistema de irrigação localizada, com gotejadores autocompensantes atuando na faixa de pressão recomendada pelo fabricante, com vazão de $2,4 \mathrm{~L} \mathrm{~h}^{-1}$, do tipo on-line inseridos no tubo, e instalados diferentes números de gotejadores por canteiro nas linhas de irrigação, de maneira a se obter as lâminas de 50, 75, 100, 125 e 150\% de reposição. Cada canteiro possuía uma linha de gotejador instalada paralelamente às linhas de plantio. Além disso, para se evitar que os tratamentos de irrigação interferissem em outros, foram enterradas lonas de polietileno longitudinalmente entre os canteiros a uma profundidade de $0,40 \mathrm{~m}$.

O controle sobre a irrigação teve como referência o tratamento de $100 \%$ de reposição de água, ou seja, quando este acusava uma tensão de $15 \mathrm{kPa}$, de maneira a se elevar a umidade do solo à capacidade de campo $(10 \mathrm{kPa})$, considerandose a profundidade efetiva do sistema radicular de $0,25 \mathrm{~m}$. O tempo de irrigação para a lâmina referencial de $100 \%$ de reposição de água foi dado pela vazão média dos gotejadores utilizados e pelo volume de água de reposição previamente calculado, utilizando-se dados extraídos da curva de retenção de água no solo. A partir da vazão e do número de gotejadores, obtiveram-se as lâminas para os demais tratamentos.

O momento de irrigar foi definido com base na leitura de três tensiômetros instalados nas unidades experimentais, com reposição de $100 \%$ da água consumida. Os tensiômetros foram instalados a uma profundidade de $0,125 \mathrm{~m}$ e as leituras realizadas diariamente, às 09 h e às 16 h, utilizando-se um tensímetro de punção digital. As irrigações foram realizadas quando pelo menos dois valores obtidos nos medidores acusaram a tensão de $15 \mathrm{kPa}$ indicada para a reposição de $100 \%$ da água no solo.

A cultivar utilizada no experimento foi a do pepino japonês, variedade Master Green. As plantas foram obtidas por semeadura em bandejas de 128 células e, após atingirem uma altura média de $0,05 \mathrm{~m}$, foram transplantadas nas unidades experimentais (canteiros).

O experimento teve início com o transplantio das mudas no dia 29 de agosto de 2008 e término com a última colheita no dia 28 de novembro de 2008, totalizando 91 dias de cultivo. Os tratamentos de irrigação foram iniciados aos 18 dias após o transplantio (DAT), período utilizado para o pegamento e uniformização das mudas.

As adubações de plantio e cobertura foram realizadas manualmente, com base na análise química do solo e conforme recomendação da CFSEMG (1999), utilizando-se, como fontes, fosfato monoamônico, nitrato de potássio e uréia. O controle de plantas daninhas foi realizado por meio de capina manual e o controle de pragas e doenças efetuado de forma preventiva, com pulverizações periódicas de defensivos.

As plantas foram tutoradas por meio de oito fios de arame liso fixados em mourões de eucaliptos até a altura de 2,0 m; aos 40 DAT, foram retirados todos os frutos e folhas localizados até o quinto internódio das plantas; a partir do sexto internódio, permitiu-se o desenvolvimento de duas ramificações por internódio, sendo as mesmas podadas após o terceiro internódio; a retirada da gema apical (capação) foi efetuada após o $22^{\circ}$ internódio, de maneira a se evitar o crescimento indeterminado e não ultrapassando os 2,0 m de altura total dos fios de arame utilizados no tutoramento.

Os frutos começaram a ser colhidos aos 55 DAT, com intervalos de um ou dois dias, dependendo do tempo necessário para que os frutos atingissem o ponto de colheita, os quais foram contados e pesados, contabilizando apenas os frutos classificados comercialmente tendo, como características, comprimento entre 20 e $24 \mathrm{~cm}$, sem defeitos de conformação (ataque de pragas e doenças) e deformações, conforme recomendação da CESAMINAS (2009). Avaliou-se a produtividade da cultura tomando-se como referência o número de frutos e a massa (peso) de frutos produzida por planta, de acordo com cada tratamento, sendo esses submetidos à análise de variância a 1 e $5 \%$ de significância através de regressão, realizadas com o software Sisvar 5.0.

Para obtenção da função de produção utilizou-se uma análise de regressão entre a variável dependente (produção comercial "Y" em kg ha-1) e a variável independente (lâminas de reposição de água "W" dadas em mm) através de um modelo polinomial do segundo grau.

Obteve-se a rentabilidade econômica pela diferença entre a receita bruta $\left(\mathrm{P}_{\mathrm{y}} \cdot \mathrm{Y}\right)$ e o custo total $\left(\mathrm{P}_{\mathrm{w}} \cdot \mathrm{W}+\mathrm{C}\right)$ para a exploração da cultura, conforme Eq. 2.

$$
\mathrm{L}(\mathrm{W})=\mathrm{P}_{\mathrm{y}} \cdot \mathrm{Y}-\left(\mathrm{P}_{\mathrm{w}} \cdot \mathrm{W}+\mathrm{C}\right)
$$

em que:

$$
\begin{aligned}
& \mathrm{L}(\mathrm{W}) \text { - lucro, } \mathrm{R} \$ \\
& \mathrm{P}_{\mathrm{w}} \text { - preço do fator água, } \mathrm{R} \$ \mathrm{~mm}^{-1} \\
& \mathrm{P}_{\mathrm{y}} \text { - preço do produto, } \mathrm{R} \$ \mathrm{~kg}^{-1} \\
& \mathrm{C} \text { - custo dos fatores fixos, } \mathrm{R} \$ \mathrm{ha}^{-1}
\end{aligned}
$$

O preço do produto $\left(\mathrm{P}_{\mathrm{y}}\right)$ correspondeu ao preço médio obtido pelo produtor rural, no Estado de Minas Gerais, no mês de março de 2009, ou seja, de $\mathrm{R} \$ 2,62 \mathrm{~kg}^{-1}$ (CEASAMINAS, 2009). Obteve-se o preço do fator água $\left(\mathrm{P}_{\mathrm{w}}\right)$ considerando-se os custos de energia, mão-de-obra, manutenção e reparos de um sistema de bombeamento, fixando alguns parâmetros e condições típicas da agricultura regional, como: irrigação localizada por gotejamento; área de $10.000 \mathrm{~m}^{2} ; 18.000$ plantas por hectare; fonte de água próximo da área de cultivo; altura manométrica total de 50 m.c.a.; vazão da motobomba de 10,31 $\mathrm{m}^{3} \mathrm{~h}^{-1}$; eficiência do conjunto motobomba de $50 \%$ e vida útil do sistema de irrigação de 10 anos. Nessas condições, o custo do sistema de irrigação foi de $\mathrm{R} \$ 6.420,00$, incluídas todas as obras necessárias.

Para obtenção do custo da energia elétrica de bombeamento da água, foram considerados os investimentos, as características do sistema de irrigação descritas acima e um ciclo de 90 dias de cultivo. $\mathrm{O}$ valor do $\mathrm{kWh}$ fornecido pela concessionária de energia elétrica (CEMIG) para o mês de março de 2009 foi de $\mathrm{R} \$ 0,29$. O custo da água aplicada foi calculado dividindo-se o custo operacional efetivo (manutenção, 
operação e energia consumida pelo sistema de irrigação) pelas lâminas totais aplicadas em cada tratamento de reposição de água.

Os fatores constantes no experimento foram orçados em $\mathrm{R} \$$ 21.511,84. Para se obter a máxima receita líquida, esses fatores foram somados aos custos operacionais efetivos $\left(\mathrm{P}_{\mathrm{w}} \mathrm{W}\right)$ conforme as lâminas de irrigação, para o cálculo do preço do fator água e, posteriormente, foram subtraídos do valor obtido com a máxima receita bruta $\left(\mathrm{P}_{\mathrm{y}} \mathrm{Y}\right)$.

Para obtenção do lucro visando à máxima produtividade, calculou-se a derivada de primeira ordem da Eq. 2 em relação a W e se igualou a zero (Eq. 3);

$$
\frac{\partial \mathrm{LW}}{\partial \mathrm{W}}=\mathrm{P}_{\mathrm{y}} \cdot \frac{\partial \mathrm{Y}}{\partial \mathrm{W}}-\mathrm{P}_{\mathrm{w}}=0
$$

entretanto, tal lucro se maximiza quando esta equação é igualada à relação entre os preços do fator água $\left(\mathrm{P}_{w}\right)$ e do pepino japonês $\left(\mathrm{P}_{\mathrm{y}}\right)$. Portanto, a função de produção gerada através de um modelo de regressão quadrática entre as variáveis " $Y$ " e "W" foi dada pela Eq. 4, obtendo-se a lâmina ótima econômica $\left(\mathrm{W}_{\text {ótima }}\right)$ a ser aplicada.

$$
\frac{\partial \mathrm{Y}}{\partial \mathrm{W}}=\mathrm{b}-2 \cdot \mathrm{c} \cdot \mathrm{W}=\frac{\mathrm{P}_{\mathrm{w}}}{\mathrm{P}_{\mathrm{y}}}
$$

A eficiência do uso da água foi determinada por meio da relação entre os valores de produção e as respectivas quantidades de água consumidas em cada tratamento.

\section{RESULTADOS E DISCUSSÃO}

De acordo com a análise de variância observada na Tabela 1, os tratamentos de irrigação sob diferentes lâminas de reposição de água no solo mostraram efeitos significativos para o número de frutos $(\mathrm{F})$ e peso dos frutos $(\mathrm{PF})$ por planta da cultura do pepino japonês.

Tabela 1. Análise de variância para as médias da produção do número de frutos e peso dos frutos $(\mathrm{kg})$, em função

\begin{tabular}{|c|c|c|c|}
\hline \multirow{2}{*}{$\begin{array}{l}\text { Fontes de } \\
\text { variação }\end{array}$} & \multirow{2}{*}{$\begin{array}{l}\text { Grau de } \\
\text { liberdade }\end{array}$} & \multicolumn{2}{|c|}{ Quadrado médio } \\
\hline & & Frutos (F) & Peso dos frutos (PF) \\
\hline $\begin{array}{l}\text { Lâmina } \\
\text { Resíduo }\end{array}$ & $\begin{array}{r}4 \\
25 \\
\end{array}$ & $\begin{array}{l}75,6406^{*} \\
26,0878 \\
\end{array}$ & $\begin{array}{l}1,0957 * \\
0,3796 \\
\end{array}$ \\
\hline \multicolumn{2}{|c|}{$\begin{array}{l}\text { Média geral } \\
\text { Coeficiente de variação }\end{array}$} & $\begin{array}{l}17,4887 \\
29,21 \%\end{array}$ & $\begin{array}{l}2,0944 \\
29,42 \%\end{array}$ \\
\hline
\end{tabular}
dos tratamentos

* Significativo a $5 \%$ de probabilidade pelo teste $\mathrm{F}$

Observa-se, por meio dos gráficos da Figura 1 (A e B), a ocorrência de queda polinomial quadrática para a produtividade, de acordo com o déficit e o excesso de água aplicada em relação à lâmina de 296,9 mm (100\%).

Pode-se notar, na Figura 1A, o número médio de 21 frutos produzidos por planta com a aplicação de lâmina
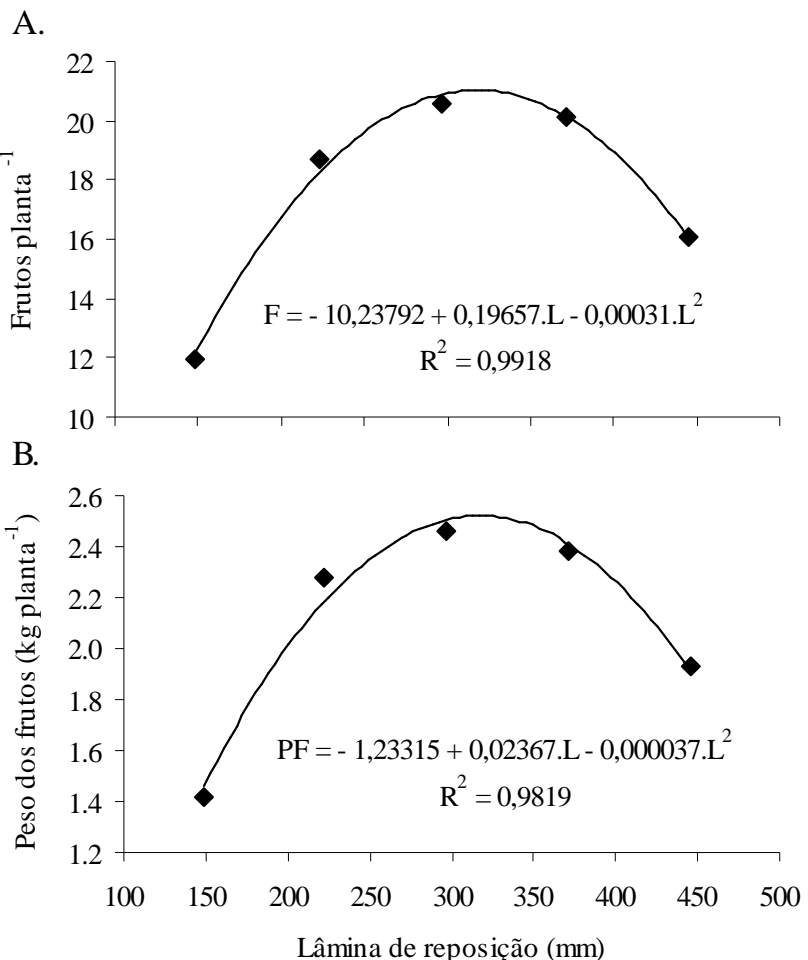

Figura 1. $N$ úmero de frutos por planta $(A)$ e peso dos frutos por planta (B) em função de diferentes lâminas de reposição de água

correspondente a 296,9 mm (reposição de $100 \%$ ), a qual tem a maior produtividade observada. O número médio de frutos $(\mathrm{F})$ obtidos referente aos outros tratamentos foi de 12; 19; 20 e 16 frutos por planta, referentes às lâminas de 148,5 mm (50\%); $222,7 \mathrm{~mm}(75 \%) ; 371,1 \mathrm{~mm}(125 \%)$ e $445,4 \mathrm{~mm}(150 \%)$, respectivamente.

Comparando a produtividade obtida pela lâmina de $100 \%$ de reposição, as maiores quedas de rendimento foram geradas pelos tratamentos de 50 e $150 \%$ de reposição. Além disso, notase que não houve variação expressiva na produção de frutos entre as lâminas de 75 a $125 \%$ de reposição, porém, de maneira geral, o déficit e o excesso hídrico afetaram a quantidade de frutos produzidos por planta do pepineiro japonês.

A Figura 1B mostra que a maior média de PF foi de $2,46 \mathrm{~kg}$ planta $^{-1}$, referente à aplicação da lâmina de 296,9 mm (reposição de $100 \%$ ). Pouca diferença foi observada em relação à $\mathrm{PF}$ produzida pelos tratamentos com reposição de 75 e $125 \%$ de água, os quais apresentaram rendimento médio de 2,28 e 2,38 kg planta $^{-1}$, respectivamente. Uma redução mais distinta quando comparada com a do tratamento de $100 \%$, foi notada para a lâmina de $150 \%$ de reposição, que obteve rendimento médio de $1,93 \mathrm{~kg}$ planta $^{-1}$; entretanto, o valor de $1,42 \mathrm{~kg}$ planta $^{-1}$ gerado pelo tratamento de $50 \%$ obteve a redução mais expressiva, observando-se que o déficit hídrico acumulado ocasionou a murcha permanente de algumas plantas, prejudicando sua fisiologia e consequente queda de produtividade. Já o excesso de umidade em torno do sistema radicular da planta dificulta o arejamento e provoca, assim, anomalias de origem fisiológica e a lixiviação de nutrientes; desta forma, onera a cultura sem nenhum beneficio, representando também desperdício de água e energia, dois sérios problemas no mundo atual (Filgueira, 2003). 
Corroborando com os presentes resultados, a redução do rendimento com reposições excessivas de água no solo também foi verificada por Santana et al. (2009), para a cultura do feijoeiro. Azevedo et al. (2005) verificaram que a produtividade da pimenteira aumentou em função do incremento das lâminas de água $(120 ; 100 ; 80 ; 60$ e 40\% da ETCA) de forma linear, obtendose produtividade máxima com aplicação da lâmina equivalente a $120 \%$ da ETCA. Trabalhando com pimentão irrigado e três níveis de lâmina (50, 75 e 100\% de ETc) como tratamentos, Gadissa \& Chemeda (2009) verificaram que o número de frutos foi maior nos tratamentos irrigados com $100 \%$ de ETc.

Ainda de maneira semelhante aos resultados obtidos neste trabalho, Duzdemir et al. (2009) notaram que a ervilha submetida ao estresse hídrico ocasionou perdas no rendimento da cultura. Do mesmo modo, Endres et al. (2010) observaram que o déficit hídrico aplicado para a cultura do feijão acarretou sensível redução da produtividade, fato observado também por Santana et al. (2009), para a cultura do feijoeiro comum cv. Talismã.

Durante a condução do experimento a temperatura média do ar no interior da casa de vegetação foi de $25,8{ }^{\circ} \mathrm{C}$, com mínimas entre 9,1 e $22,7^{\circ} \mathrm{C}$ e máximas entre 21,8 e $42,7^{\circ} \mathrm{C}$. A umidade relativa média do ar foi de $56 \%$, com máximas entre 56 e $87 \%$ e mínimas entre 16 e $66 \%$. Tais condições climáticas, fora da faixa ótima (Sganzerla, 1995), podem ter afetado o crescimento, a floração e a frutificação das plantas, redundando em baixas produtividades, de acordo com dados técnicos para o pepino. A mesma situação foi observada por Santos (2002), que obteve produção reduzida para o pepineiro em ambiente protegido. A Figura 2 mostra as condições climáticas por meio das temperaturas (A) e umidades relativas do ar (B) durante a condução do experimento em função do tempo, a partir do início dos tratamentos, aos 18 DAT.

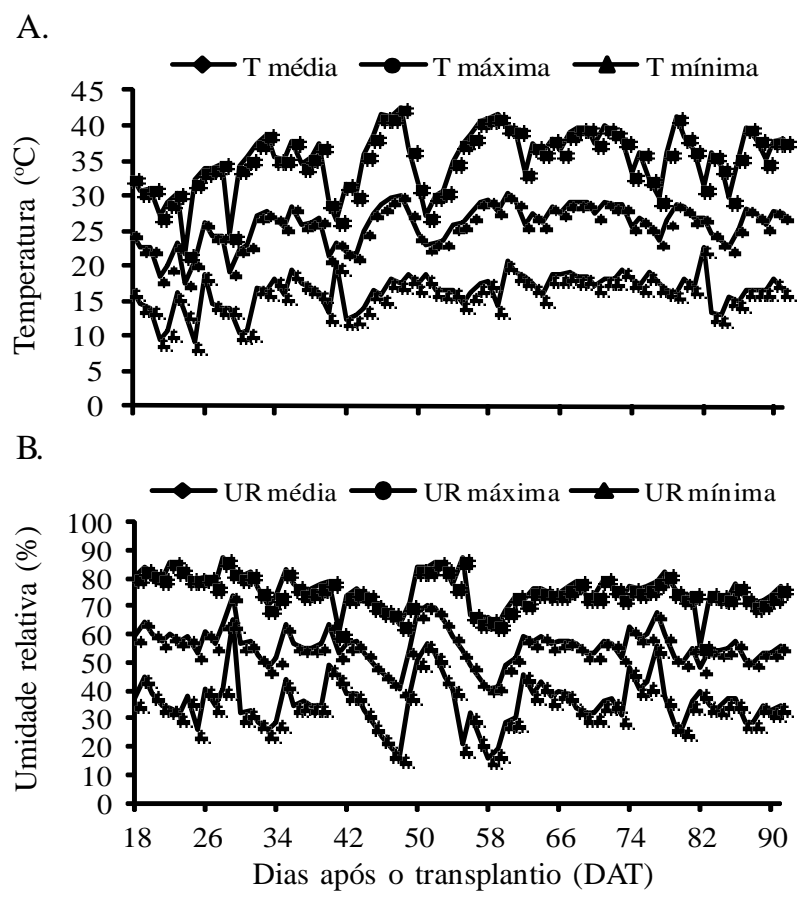

Figura 2. Temperaturas (A) e umidades relativas (B) no interior da casa de vegetação durante o experimento a partir do início dos tratamentos, aos 18 DAT
Com relação à análise econômica da produção e se considerando a hipótese de que $\mathrm{L}(\mathrm{W})$ possui um valor máximo de acordo com a Eq. 2 e que a água é o único fator variável, obtiveram-se as máximas produtividades físicas para o cultivo do pepino japonês.

A função de produção estimada mostrada na Figura 1B para a produtividade comercial foi multiplicada pelo número de plantas por hectare (18.000 plantas) para se obter a produtividade total; posteriormente, esta equação foi derivada e igualada à zero (Eq. 5), obtendo-se a máxima produtividade física do fator água.

$$
\frac{\partial \mathrm{Y}}{\partial \mathrm{W}}=-1,332 \cdot \mathrm{W}+426,06=0
$$

Observa-se, pelos dados da Tabela 2, que a máxima produtividade física do fator água, também chamada produto físico marginal (PFMa) do fator água, tem valor inicialmente positivo e decresce à medida em que se aumenta a lâmina total de irrigação aplicada ao solo.

Tabela 2. Produto físico marginal (PFMa) do fator água para as lâminas de irrigação

\begin{tabular}{cc}
\hline $\begin{array}{c}\text { Lâminas de irrigação } \\
(\mathbf{m m})\end{array}$ & $\begin{array}{c}\text { Produto físico marginal do fator água } \\
\left(\mathbf{k g ~ h a}^{-1} \mathbf{~ m m}^{-1}\right)\end{array}$ \\
148,5 & 228,3 \\
222,7 & 129,4 \\
296,9 & 30,6 \\
371,1 & $-68,2$ \\
445,4 & $-167,2$ \\
\hline
\end{tabular}

Quando o PFMa atinge o valor zero significa que a lâmina de irrigação aplicada proporcionou a máxima produtividade física, representando $45.944 \mathrm{~kg} \mathrm{ha}^{-1}$ para uma lâmina de irrigação de $320 \mathrm{~mm}$, o que equivale a 107,8\% de reposição de água no solo. A partir do ponto em que o PFMa apresentou valor nulo (320 mm), a aplicação de maior lâmina de irrigação conduziu a valores negativos, o que indica ser não econômico e irracional.

A lâmina ótima de irrigação $\left(\mathrm{W}_{\text {ótima }}\right)$ para a obtenção da máxima eficiência econômica foi calculada pela Eq. 6, o que resultou em um valor de 319,5 mm (107,6\% de reposição de água no solo), gerando uma produtividade de $45.944 \mathrm{~kg} \mathrm{ha}^{-1}$.

$$
\frac{\partial \mathrm{Y}}{\partial \mathrm{W}}=-1,332 \cdot \mathrm{W}+426,06=\frac{\mathrm{P}_{\mathrm{w}}}{\mathrm{P}_{\mathrm{y}}}
$$

Fazendo-se uma análise comparativa entre a lâmina ótima econômica e a lâmina que gera a máxima produtividade física, observam-se iguais valores de produtividade; logo, ao aplicar a lâmina de água que proporcione a máxima produção física, esta poderá ser suficiente para alcançar uma produção economicamente viável, indicando que a irrigação deve ser feita de forma a garantir a manutenção das condições ótimas de umidade no solo. Valores muito próximos entre a lâmina ótima econômica e a lâmina que gerou a maior produtividade, foram observados por Lima Júnior et al. (2010), para a cultura da alface americana irrigada. 
Por meio do gráfico da Figura 3 são mostrados os valores da receita bruta, receita líquida e os custos totais gerados através de regressões quadráticas com coeficiente de determinação $\left(\mathrm{R}^{2}\right)$ igual a $100 \%$, em função das lâminas de reposição de água no solo.

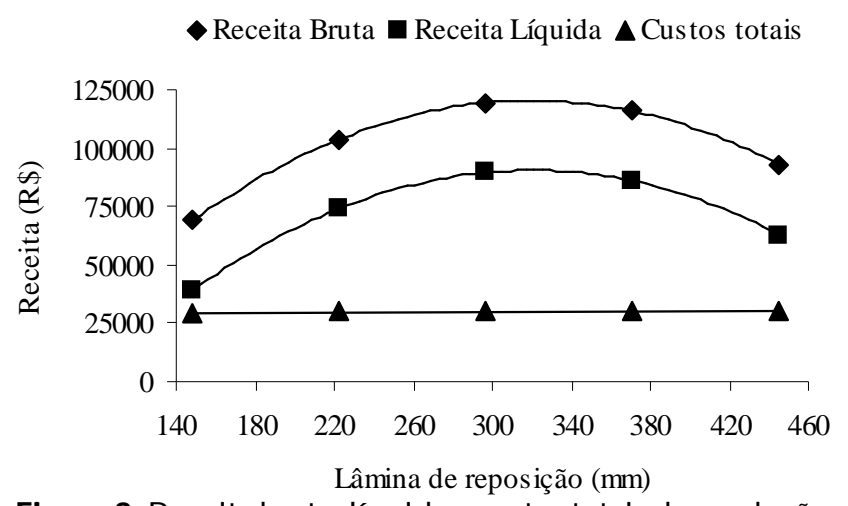

Figura 3. Receita bruta, líquida e custos totais de produção em função das lâminas de reposição

Ainda conforme a Eq. 2, a receita bruta $(\mathrm{RB})$ foi obtida por meio dos valores de cada produtividade (Y) multiplicada pelo preço do pepino japonês $\left(\mathrm{P}_{\mathrm{y}}\right)$ tomado para o mês de março de 2009; já a receita líquida (RL) foi gerada da subtração da receita bruta pelos custos totais (CT), envolvendo os custos dos fatores fixos e os custos com a variação das lâminas de reposição de água no solo (W) aplicadas. As funções de produção para a RB, RL e CT são verificadas nas Eqs. 7, 8 e 9, respectivamente.

$$
\begin{aligned}
& \mathrm{RB}=-1,7447 \cdot \mathrm{W}^{2}+1.116,038 \cdot \mathrm{W}-58.105,053 \\
& \mathrm{RL}=-1,7447 \cdot \mathrm{W}^{2}+1.115,103 \cdot \mathrm{W}-87.686,731
\end{aligned}
$$

$$
\mathrm{CT}=\mathrm{W}+29.581,670
$$

A receita líquida obtida para o máximo retorno econômico neste estudo foi de $\mathrm{R} \$ 90.488,95$, equivalente à lâmina de 320 $\mathrm{mm}$, acarretando uma produtividade de $45.944 \mathrm{~kg} \mathrm{ha}^{-1}$. Este alto valor obtido no retorno econômico pode ser justificado, uma vez que foi considerado o preço de venda do produto diretamente na propriedade, não sendo levados em conta os custos com logística, impostos pagos pelo produtor na comercialização, perdas físicas no transporte, na recepção e armazenamento do produto na central de abastecimento, dentre outras perdas decorrentes de outros fatores.

Através do gráfico da Figura 4, gerada pela Eq. 6, observase que, quando a relação $\mathrm{P}_{\mathrm{w}} / \mathrm{P}_{\mathrm{y}}$ atinge o valor zero, significa que a lâmina ótima econômica de 319,5 mm proporcionou, da mesma forma, a máxima produtividade física. Verifica-se, ainda, que a lâmina ótima decresce na medida em que se aumenta a relação $\mathrm{P}_{\mathrm{w}} / \mathrm{P}_{\mathrm{y}}$. Assim, variando o preço da água e mantendo fixo o preço do pepino japonês, a lâmina econômica total de irrigação a aplicar deve ser menor, de maneira que o produtor obtenha o lucro máximo na atividade.

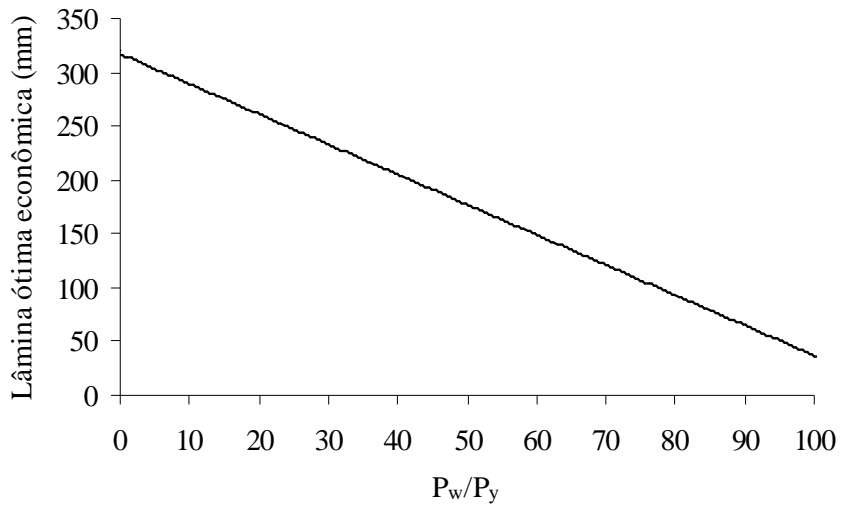

Figura 4. Lâmina ótima econômica, em função da relação entre o preço da água $\left(P_{w}\right)$ e o preço do pepino japonês $\left(P_{\mathrm{y}}\right)$, para a produtividade comercial

\section{Conclusões}

1. A produtividade da cultura foi afetada pelo déficit e excesso hídrico, de forma geral, obtendo-se os maiores valores com a reposição de $100 \%$ de água até a capacidade de campo.

2. A lâmina de $320 \mathrm{~mm}$ proporcionou a maior produtividade física com $45.944 \mathrm{~kg} \mathrm{ha}^{-1}$, equiparando-se à maior rentabilidade econômica obtida com a lâmina de $319,5 \mathrm{~mm}$.

\section{LITERATURA CITADA}

Albuquerque Filho, J. A. C. de; Lima, V. L. A. de; Menezes, D.; Azevedo, C. A. V.; Dantas Neto, J.; Silva Júnior, J. G. da. Características vegetativas do coentro submetido a doses do polímero hidroabsorvente e lâminas de irrigação. Revista Brasileira de Engenharia Agrícola e Ambiental, v.13, p.671679, 2009.

Alencar, C. A. B. de; Oliveira, R. A. de; Cóser, A. C.; Martins, C. E.; Cunha, F. F. da; Figueiredo, J. L. A. Produção de capins cultivados sob pastejo em diferentes lâminas de irrigação e estações anuais. Revista Brasileira de Engenharia Agrícola e Ambiental, v.13, p.680-686, 2009.

Azevedo, B. M. de; Chaves, S. W. P.; Medeiros, J. F. de; Aquino, B. F. de; Bezerra, F. M. L.; Viana, T. V. de A. Rendimento da pimenteira em função de lâminas de irrigação. Ciência Agronômica, v.36, p.268-273, 2005.

Bilibio, C.; Carvalho, J. A.; Martins, M.; Rezende, F. C.; Freitas, E. A.; Gomes, L. A. A. Desenvolvimento vegetativo e produtivo da berinjela submetida a diferentes tensões de água no solo. Revista Brasileira de Engenharia Agrícola e Ambiental, v.14, p.730-735, 2010.

Carvalho, J. de A.; Santana, M. J. de; Pereira, G. M.; Pereira, J. R. D.; Queiroz, T. M. de. Níveis de déficit hídrico em diferentes estádios fenológicos da cultura de berinjela (Solanum melongena L.). Engenharia Agrícola, v.24, p.320327, 2004.

CESAMINAS - Centrais de Abastecimento. Boletim diário de preços. <http://minas.ceasa.mg.gov.br/detec/boletim/ boletim_produto/boletim_produto.php>. 31 mar. 2009. 
CFSEMG - Comissão de Fertilidade do Solo do Estado de Minas Gerais. Recomendações para o uso de corretivos e fertilizantes em Minas Gerais: 5a aproximação. Viçosa: UFV, 1999. 359p.

Dantas, A. A. A.; Carvalho, L. G.; Ferreira, E. Classificação e tendência climática em Lavras, MG. Ciência e Agrotecnologia, v.31, p.1862-1866, 2007.

Dermitas, C.; Ayas, S. Deficit irrigation effects on pepper (Capsicum annuиm L. Demre) yield in unheated greenhouse condition. Journal of Food, Agricultural and Environment, v.7, p.989-1003, 2009.

Dourado Neto, D.; Nielsen, D. R.; Hopmans, J. W.; Reichardt, K.; Bacchi, O. O. S. Software to model soil water retention curves (SWRC, version 3.00). Scientia Agricola, v.57, p.191-192, 2000.

Duzdemir, O.; Kurunc, A.; Unlukara, A. Response of pea (Pisum sativum) to salinity and irrigation water regime. Bulgarian Journal of Agricultural Science, v.15, p.400-409, 2009.

Endres, L.; Souza, J. L. de; Teodoro, I.; Marroquim, P. M. G.; Santos, C. M. dos; Brito, J. E. D. de. Gas exchange alteration caused by water deficit during the bean reproductive stage. Revista Brasileira de Engenharia Agrícola e Ambiental, v.14, p.11-16, 2010.

Ferguson, C. E. Teoria micro-econômica. 11.ed. Rio de Janeiro: Forense Universitária, 1988. 609p.

Filgueira, F. A. R. Novo manual de olericultura: Agrotecnologia moderna na produção e comercialização de hortaliças. 2.ed. Viçosa: UFV, 2003. 412p.

Gadissa, T.; Chemeda, D. Effects of drip irrigation levels and planting methods on yield and yield components of green pepper (Capsicum annuum, L.) in Bako, Ethiopia. Agricultural Water Management, v.96, p.1673-1678, 2009.

Lima Júnior, J. A. de; Pereira, G. M.; Geisenhoff, L. O.; Costa, G. G.; Vilas Boas, R. C.; Yuri, J. E. Efeito da irrigação sobre o rendimento produtivo da alface americana, em cultivo protegido. Revista Brasileira de Engenharia Agrícola e Ambiental, v.14, p.797-803, 2010.
Monteiro, R. O. C. Função de resposta da cultura do meloeiro aos níveis de água e adubação nitrogenada no vale do Curu, CE. Fortaleza: UFC, 2004. 87p. Dissertação Mestrado

Santana, M. J. de; Carvalho, J. A.; Andrade, M. J. B. de; Gervásio, G. G; Braga, J. C.; Lepri, E. B. Viabilidade técnica e econômica da aplicação de água na cultura do feijoeiro comum (Phaseolus vulgaris L.). Ciência e Agrotecnologia, v.33, p.532-538, 2009.

Santos, D. S. Efeitos da tensão de água no solo, na cultura do pepino (Cucumis sativus L.), utilizando sistema de irrigação automatizado. Lavras: UFLA, 2002. 60p. Dissertação Mestrado

Sganzerla, E. Nova agricultura: A fascinante arte de cultivar com os plásticos. 5.ed. Guaíba: Agropecuária, 1995. 342p.

Silva, P. A. M.; Pereira, G. M.; Reis, R. P.; Lima, L. A.; Taveira, J. H. da S. Função de resposta da alface americana aos níveis de água e adubação nitrogenada. Ciência e Agrotecnologia, v.32, p.1266-1271, 2008.

van Genuchten, M. T. A closed-form equation for predicting the hydraulic conductivity of unsaturated soils. Soil Science Society of America Journal, v.44, p.892-898, 1980.

Vilas Boas, R. C.; Carvalho, J. de A.; Gomes, L. A. A.; Sousa, A. M. G. de; Rodrigues, R. C.; Sousa, K. D. de. Avaliação técnica e econômica da produção de duas cultivares de alface tipo crespa em função de lâminas de irrigação. Ciência e Agrotecnologia, v.32, p.525-531, 2008.

Vilas Boas, R. C.; Carvalho, J. de A.; Gomes, L. A. A.; Sousa, K. J.; Rodrigues, R. C.; Sousa, A. M. G. Efeito da irrigação no desenvolvimento da alface crespa, em ambiente protegido, em Lavras, MG. Revista Brasileira de Engenharia Agrícola e Ambiental, v.11, p.393-397, 2007.

Zeng, C.; Bie, Z.; Yuan, B. Determination of optimum irrigation water amount for drip-irrigated muskmelon (Cucumis melo, L.) in plastic greenhouse. Agricultural Water Management, v.96, p.595-602, 2009. 